\title{
Andreyivanovite: A Second New Phosphide from the Kaidun Meteorite
}

Michael Zolensky, Code KT, NASA Johnson Space Center, Houston, Texas 77058, U.S.A.

Matthieu Gounelle, Muséum National d'Histoire Naturelle, 57 rue Cuvier, 75005 Paris cedex, France

Takashi Mikouchi, Mineralogical Institute, Faculty of Science, University of Tokyo, Hongo, Bunkyo-Ku, Tokyo 113, Japan

Kazumasa Ohsumi, Institute of Materials Structure Science, Tsukuba-shi, Ibaraki-ken, 305, Japan

Loan Le, Jacobs Sverdrup Co., Houston, TX 77058, USA

Kenji Hagiya, Graduate School of Life Science, University of Hyogo., Japan

and

Osamu Tachikawa, Mineralogical Institute, Faculty of Science, University of Tokyo, Hongo, Bunkyo-Ku, Tokyo 113, Japan

Re-revised MS submitted January 2008 


\begin{abstract}
Andreyivanovite (ideally $\mathrm{FeCrP}$ ) is another new phosphide species from the Kaidun meteorite, which fell in South Yemen in 1980. Kaidun is a unique breccia containing an unprecedented variety of fragments of different chondritic as well as achondritic lithologies. Andreyivanovite was found as individual grains and linear arrays of grains with a maximum dimension of $8 \mu \mathrm{m}$ within two masses of Fe-rich serpentine. In one sample it is associated with Fe-Ni-Cr sulfides and florenskyite (FeTiP). Andreyivanovite is creamy white in reflected light, and its luster is metallic. The average of nine electron microprobe analyses yielded the formula $\mathrm{Fe}\left(\mathrm{Cr}_{0.587} \mathrm{Fe}_{0.150} \mathrm{~V}_{0.109} \mathrm{Ti}_{0.081} \mathrm{Ni}_{0.060} \mathrm{Co}_{0.002}\right) \mathrm{P}$. Examination of single grains of andreyivanovite using Laue patterns collected by in-situ synchrotron X-ray diffraction (XRD), and by electron backscattered diffraction revealed that it is isostructural with florenskyite; we were unable to find single crystals of sufficient quality to perform a complete structure analysis. Andreyivanovite crystallizes in the space group Pnma, and has the anti- $\mathrm{PbCl}_{2}$ structure. Previously-determined cell constants of synthetic material $[a=5.833(1), b=3.569(1), c=6.658(1) \AA]$ were consistent with our XRD work. We used the XPOW program to calculate a powder XRD pattern; the 5 most intense reflections are $d=2.247(I=100), 2.074$ (81), 2.258 (46), 1.785 (43), and $1.885 \AA$ (34). Andreyivanovite is the second new phosphide to be described from the Kaidun meteorite. Andreyivanovite could have formed as a result of cooling and crystallization of a melted precursor consisting mainly of Fe-Ni metal enriched in $\mathrm{P}$, Ti, and $\mathrm{Cr}$. Serpentine associated with andreyivanovite would then have formed during aqueous alteration on the parent asteroid. It is also possible that the andreyivanovite could have formed during aqueous alteration, however, artificial FeTiP has been synthesized only during melting experiments, at low oxygen fugacity, and there is no evidence that a hydrothermal genesis is reasonable.
\end{abstract}

\title{
Introduction
}

The Kaidun meteorite is unique in being a breccia of enormously varied extraterrestrial materials, including carbonaceous chondrites (CI, CM, CV), enstatite chondrites (EH, EL), Rumuruti chondrites, ordinary chondrites, basaltic achondrites, and an equal number of new lithologies with unknown affinities (Ivanov, 1989; Zolensky and Ivanov, 2003). As such this single meteorite, with a total mass of only $842 \mathrm{~g}$, samples a greater swath of the solar system than any other known rock. Kaidun was recovered immediately after its observed fall in South Yemen in 1980; therefore formation of terrestrial minerals within the meteorite (beyond those in rust) is basically precluded. As might be expected in such a complex rock, there are numerous new minerals in Kaidun, which are only slowly receiving adequate characterization. Chief among these are new phosphides and sulfides situated in aqueously altered clasts.

In the course of an examination of sample $3.10 \mathrm{j}$ of the Kaidun meteorite, we encountered linear groupings of lozenge-shaped crystals of essentially stoichiometric FeCrP, a previously unknown mineral (Figure 1). The phosphide crystals criss-cross a clast of serpentine, exactly as we found for florenskyite (FeTiP) in the same meteorite (Ivanov et al. 2000). At the time we described florenskyite we in fact noted very small crystals of several associated phosphides and sulfides, including a Fe-Cr phosphide, which were too small to adequately characterize. The new sample presented an opportunity to completely characterize the FeCrP phase.

The mineral is named for Andrey Ivanov (b 1937), Russian geochemist and mineralogist, who was one of the principal investigators for the Luna missions, and has been the most faithful friend of the wonderful Kaidun meteorite. The new mineral and the name have been approved by the Commission on New Minerals and Mineral Names of the IMA. The type polished section 
(3.10j) containing andreyivanovite is deposited at the Curation Facility, NASA Johnson Space Center, Houston, Texas, U.S.A. Another section of the Kaidun meteorite (53.10) containing grains of andreyivanovite is held at the Vernadski Institute, Moscow, Russia.

\section{Experimental Techniques}

All work was performed on Kaidun section 3.10j, a potted butt in epoxy, which is archived at the Johnson Space Center, in the Astromaterials Research and Exploration Science Division. The undamaged section remains there now, and is available for future investigations.

The composition of the sample was studied in detail using a CAMECA SX100 electron microprobe operated at a voltage acceleration of $15 \mathrm{kV}$, beam current of $10 \mathrm{nA}$ and with a 2 micron focused beam. Standard calibration and correction procedures were applied. Natural mineral standards were used. All major elements were determined with an accuracy of better than $1 \%$ relative.

We first attempted to collect single crystal Laue patterns of individual crystals, using a Laue camera, as we had previously successfully done for florenskyite. These investigations were performed on crystals still lodged within the thin section, and were truly non-destructive. We examined several separate FeCrP crystals by the Laue SXRD method using polychromatic synchrotron radiation at beamline 4B of the Photon Factory, National Laboratory for High Energy Physics (KEK), Tsukuba, Japan. The Laue diffraction experiment was performed with the following conditions. The ring operated at $2.5 \mathrm{GeV}$. The exposure times were 60 minutes. We used polychromatic radiation at $0.3 \sim 3.0 \AA$. The beam size at the sample position was 1.6 $\mu \mathrm{m}$ in diameter, with a beam divergence of $40 \mu \mathrm{rad}$. These procedures are described in detail by Ivanov et al. (2000).

Electron back-scatter diffraction (EBSD) pattern (Kikuchi diffraction pattern) analysis provides crystallographic and phase information of micrometer-sized crystalline materials prepared for observation in an SEM (Goehner and Michael 1996). Back-scattered electrons form an EBSD pattern on a phosphor screen distant from the specimen. The incident electrons are scattered mainly by phonons in the specimen with a large scattering angle and a small energy loss. These divergent electrons in the specimen are scattered again to form Kikuchi bands at certain angles.

Several grains of the $\mathrm{FeCrP}$ phase in Kaidun were successfully analyzed by a ThermoNoran PhaseID EBSD system installed into Hitachi S-4500 FEG-SEM equipped with a Kevex Sigma energy-dispersive X-ray spectrometer (EDS), at the Department of Earth and Planetary Science, University of Tokyo. The accelerating voltage of the incident beam was 20 $\mathrm{kV}$, and the beam current was 2-3 nA. The collection semi-angle of the EBSD detector was $\sim 37.5^{\circ}$. The thin section was coated with amorphous carbon to maintain electrical conductivity. The section was tilted by $\sim 70^{\circ}$ from the horizontal toward the phosphor screen (the detector) using a specimen mount. Calculations of Kikuchi patterns and analyses of observed EBSD patterns were performed using a computer program developed by Kogure (2003).

We calculated the powder X-ray diffraction pattern for andreyivanovite using the XPOW program (Downs et al., 1993).

\section{Occurrence}

The new mineral was located in two sections of Kaidun, in both cases with the same associations. We first encountered it during our investigation of florenskyite in Kaidun section 
53.10, where it was too fine-grained to permit detailed characterization. Figure 1 shows the sample (in section $3.10 \mathrm{j}$ ) that was finally found to contain sufficiently large crystals to permit proper analysis (by microprobe and EBSD). Figure 2 shows the occurrence of andreyivanovite we originally discovered (section 53.10), where it is associated with florenskyite. The bulk of both of these particular Kaidun samples consists of type 1 and 2 carbonaceous chondrite meteorite lithlogies of uncertain affinities. In fact Kaidun is a microbreccia of many meteorite types, so proximity of the new mineral-bearing clast with these particular carbonaceous chondrite lithologies does not guarantee a genetic relationship.

As can be seen in Figure 1, there are linearly-arrayed crystals of Fe-Ni-Cr sulfides and the new mineral which cross the serpentine mass. The largest observed crystal of the new phosphide measures $\sim 5 \times 8 \mu \mathrm{m}$. In reflected light andreyivanovite is creamy white and the luster is metallic. The small grain size prevented the accurate measurement of some physical and optical properties of the mineral, including reflectivity and density.

In both known samples, andreyivanovite sits within a matrix of rather Fe-rich serpentine containing micrometer-sized Fe-Ni sulfides (Table 2). In one sample (53.10) it is also associated with Fe-Ni-Cr sulfides and florenskyite (FeTiP) (Figure 2), and in the other sample only (3.10j) the $\mathrm{Fe}-\mathrm{Ni}-\mathrm{Cr}$ sulfides are apparent (Figure 1).

\section{Composition}

The clasts enclosing the new mineral consist mainly of Fe-rich serpentine, whose compositions are given in Table 2. Directly adjacent to the andreyivanovite grains in both occurrences the surrounding serpentine carries a significant amount of $\mathrm{S}$ (Tables 1 and 2), which must be due to a high, and rather uniform quantity of sub-micron sized $\mathrm{Fe}-\mathrm{Ni}$ sulfide grains. Pentlandite is ubiquitous within aqueously altered clasts in Kaidun (Zolensky and Ivanov, 2003), and adjacent to some grains of andreyivanovite there are micron-and larger-sized grains of a still uncharacterized Fe-Ni-Cr sulfide. Microprobe analyses of 9 grains of andreyivanovite in section $3.10 \mathrm{j}$ indicated a consistent composition, but were all complicated from interference by surrounding sulfide-bearing, Fe-rich serpentine. Since we were not able to obtain analysis of solely this phosphide phase, we had to subtract the average composition of the enclosing matrix to yield a reliable composition. To do this we used an average of 9 phosphide analyses, and 10 of adjacent matrix. We assumed that all $\mathrm{Si}$ in the phosphide was due to serpentine contamination, and, normalizing to Si, subtracted the average serpentine composition. Residuals for S, Al and $\mathrm{Mg}$ were all between 0.001 and -0.001 , convincing us that this calculation was valid. We note that the average matrix composition of the original occurrence of andreyivanovite in Kaidun (section 53.10), which was published in the paper describing florenskyite (Ivanov et al., 2000), is quite similar to that in section $3.10 \mathrm{j}$, with the exception of $\mathrm{Cr}_{2} \mathrm{O}_{3}$ (Table 2).

The average composition of the new mineral was $\mathrm{Fe}\left(\mathrm{Cr}_{0.587} \mathrm{Fe}_{0.150} \mathrm{~V}_{0.109} \mathrm{Ti}_{0.081} \mathrm{Ni}_{0.060}\right.$ $\left.\mathrm{Co}_{0.002}\right) \mathrm{P}$, which can be abbreviated by the ideal formula $\mathrm{FeCrP}$. Cations were grouped in the proposed formula based upon analogies to the stoichiometry of other phosphides. It was assumed that one cation site is completely occupied by Fe, in analogy to other phosphides including florenskyite. It is possible that some Si truly belongs in andreyivanovite, due to its preference for tetrahedral coordination, as in perryite, but this is probably not very significant, and in any case this issue cannot be resolved at this time.

\section{Crystal Structure}


As enumerated by Rundqvist and Nawapong (1966), there are a whole raft of MIMIIP compounds (including $\mathrm{FeCrP}$, with the anti- $\mathrm{PbCl}_{2}$ structure), none of which were (at that time) known from nature. Rundqvist and Nawapong (1966) determined the structure of the related compound FeZrP, and synthesized related compounds, including FeCrP, but did not refine its structure. Unit cell FeCrP parameters for synthetic FeCrP were determined by Kumar et al. (2004) to be $a=5.833, b=3.569, c=6.658 \AA$, space group Pnma, and $Z=4$. Given the fact that the available crystals of andreyivanovite were a few microns in size, and that we could find only a few small crystals, conventional XRD is insufficient for structure refinements. We therefore used in-situ single-crystal Laue diffraction work using synchrotron radiation (SXRD). We used this same technique to successfully verify the structure of florenskyite (FeTiP) (Ivanov et al., 2000). The andreyivanovite grains were analyzed in the thin section. The small beam diameter permitted us to select discrete regions of the individual andreyivanovite crystals for data collection.

We collected Laue patterns from the three largest FeCrP grains, whose morphology suggested that they were single crystals. Unfortunately, the Laue patterns revealed that the investigated grains were all polycrystalline. The best Laue pattern we obtained (Figure 3), which had the sharpest diffraction spots, showed the presence of 4 domains in nearly the same orientation. We attempted to index this pattern using the florenskyite (FeTiP) structure as a model, and previously-reported cell constants from artificial FeCrP. This analysis was successful, although the polycrystalline nature of the new mineral precluded use of the Laue pattern to perform a full structure analysis.

Thus we then attempted to verify the structure of the new mineral using the EBSD technique. Figure 4 shows the best EBSD pattern that we rather easily obtained. Comparison of the crystal structures of florenskyite, allabogdanite, and other phosphides revealed that the new phosphide has the same basic diffraction pattern as florenskyite, meaning that the two minerals are isostructural, as suggested by previous work on artificial material (Rundqvist and Nawapong, 1966). Thus andreyivanovite crystallizes in the space group $\mathrm{Pnma}$, and has the anti- $\mathrm{PbCl}_{2}$ structure. Previously-determined cell constants of synthetic material $(a=5.833(1), b=3.569(1)$, $c=6.658(1) \AA$ ) (Kumar et al., 2004) were consistent with the present XRD work (Table 3), although the precision of the cell constants determined by Kumar et al. on the synthetic material were far superior to the data we could obtain from the natural material. Thus we used the published cell constants in the calculation of the powder X-ray pattern using the XPOW program (Downs et al., 1993). The 5 most intense calculated diffraction reflections are $d=2.247(I=$ 100), 2.074 (81), 2.258 (46), 1.785 (43), and $1.885 \AA$ (34) (Table 4).

\section{Discussion}

Andreyivanovite occurs in the Kaidun meteorite within two clasts of Fe-rich serpentine whose composition is very similar to the observed products of asteroidal aqueous alteration in other highly altered lithologies in Kaidun (Ivanov et al., 1993; Zolensky and Ivanov, 2003). The precursor material for the serpentine in this particular Kaidun lithology plausibly included olivine, pyroxene, Fe-Ni metal containing schreibersite, and Fe-Ni sulfides; such a mineral assemblage is common to many unaltered chondritic meteorites (Zolensky and McSween, 1988; Zolensky et al. 1997; Krot et al. 1998). In most altered chondrites this lithology is typically replaced by phyllosilicates dotted with sulfides, oxides and phosphates. The unusual feature of the Kaidun lithology is the presence of $\mathrm{Fe}-\mathrm{Ti}-\mathrm{Cr}-\mathrm{Ni}-\mathrm{V}$ phosphides rather than Ca phosphates. As can be seen in Figures 1 and 2, crystals of $\mathrm{Fe}-\mathrm{Cr}$ sulfides and the new mineral occur in 
curvilinear arrays which cross the serpentine clast, which suggests that they could have formed by exsolution. It is not possible to propose a definite paragenesis for the phosphides from the available information. Somehow, Fe-Ti-Cr-Ni-V phosphides formed here rather than the assemblage Fe-Ni metal, schreibersite, daubreelite $\left(\mathrm{FeCr}_{2} \mathrm{~S}_{4}\right)$, osbornite $(\mathrm{TiN})$, and/or heideite $\left[(\mathrm{Fe}, \mathrm{Cr})(\mathrm{Ti}, \mathrm{Fe})_{2} \mathrm{~S}_{4}\right]$, all of which are usually present in enstatite chondrite lithologies in Kaidun which display varying degrees of aqueous alteration (Zolensky and Ivanov, 2003).

Partial loss of volatile components such as $\mathrm{S}$ or $\mathrm{N}$ could have accompanied the hypothesized melting. Andreyivanovite could have formed as a result of cooling and crystallization of a melted precursor consisting mainly of $\mathrm{Fe}-\mathrm{Ni}$ metal enriched in $\mathrm{P}$, $\mathrm{Ti}$, and $\mathrm{Cr}$, and the presence of andreyivanovite and not florenskyite in Kaidun section $3.10 \mathrm{j}$ could be due to an original heterogeneity in $\mathrm{Ti}$ of the precursor. These phosphide-containing lithologies would then have experienced aqueous alteration on the parent asteroid, which resulted in production of the serpentine. Ti-Cr rich phosphides must have been stable during such alteration. It is also possible that the phosphides formed during aqueous alteration. However, artificial FeTiP has been synthesized only during melting experiments, at low oxygen fugacity (Rundqvist and Nawapong, 1966; Kumar et al., 2004), and there is no evidence that a hydrothermal genesis is reasonable.

\section{Acknowledgments}

This study was supported by NASA grant 152-11-40-23 to M.E.Z. Gene Jarosewich provided the phosphide microprobe standard, and Craig Schwandt advised on trickier aspects of the microprobe calibration process. We thank Peter Buseck, Tim McCoy and Rhian Jones for careful reviews of the manuscript. Masamichi Miyamoto provided the facilities of the Mineralogical Institute, at Tokyo University, at great potential risk to his reputation.

\section{References}

Downs R. T., Bartelmehs K.L., Gibbs G. V., and Boisen M. B. Jr. (1993) Interactive software for calculating and displaying X-ray or neutron powder diffractometer patterns of crystalline materials. American Mineralogist 78, 1104-1107.

Goehner R. P. and Michael J. R. (1996) Phase identification in a scanning electron microscope using backscattered electron Kikuchi patterns. Journal of Research of National Institute of Standards and Technology 101, 301-308.

Ivanov A.V. (1989) Meteorit Kaidun: Sostav i istoriya formirovaniya (The Kaidun meteorite: Composition and history of formation). Geokhimiya, no 2, 259-266.

Ivanov, A.V., Kononkova, N.N., and Guseva, Ye.V. (1993) Hydrothermal alteration of schreibersite and metallic iron in Kaidun III meteorite (EH5). Geochemistry International 30, 11-19.

Ivanov A.V., Zolensky M.E., Saito A., Ohsumi K., MacPherson G.J., Yang S.V., Kononkova N.N. and Mikouchi T. (2000) Florenskyite, FeTiP, a new phosphide from the Kaidun meteorite, American Mineralogist 85,1082-1086.

Kogure T. (2003) A program to assist Kikuchi pattern analysis. Journal of the Crystallographic Society of Japan 45, 391-395 (in Japanese with English abstract).

Krot, A.N., Petaev, M.I., Scott, E. R. D., Choi, B-G., Zolensky, M.E., and Keil, K. (1998) Progressive alteration in CV3 chondrites: More evidence for asteroidal origin. Meteoritics and Planetary Science 33, 1065-1085. 
Kumar S., Krishnamurthy A., Bipin K. Srivastava K., Daa A. and Paranjpe S. (2004) Magnetization and neutron diffraction studies on FeCrP. Pramana 63, 199-205.

Rundqvist, S. and Nawapong, P.C. (1966) The crystal structure of ZrFeP and related compounds. Acta Chemica Scandinavica 20, 2250-2254.

Zolensky M.E. and Ivanov A. (2003) The Kaidun microbreccia meteorite: A harvest from the inner and outer asteroid belt. Chemie de Erde 63, 185-246.

Zolensky, M.E., Krot, A.N., and Scott, E.R.D. (Eds.) (1997) Workshop on Modification of Chondritic Materials, LPI Technical Report 97-02, 71 p.

Zolensky, M.E. and McSween, H.Y. (1988) Aqueous alteration. In J. Kerridge and M. Matthews, Eds., Meteorites and the Early Solar System, p.114-143. University of Arizona Press, Tucson. 
Table 1. Microprobe analyses of contaminated FeCrP, matrix, and matrix-subtracted FeCrP, all from section 3.10j

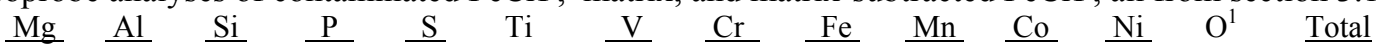

$\mathrm{FeCrP}$

Rough $^{2}$

$0.29 \quad 0.02$

$\begin{array}{lll}0.89 & 20.67 & 0.20\end{array}$

$2.60 \quad 3.70$

$\begin{array}{lllll}21.33 & 50.54 & 0.09 & 0.33 & 3.82\end{array}$

104.48

Matrix $^{3}$

$2.53 \quad 0.1$

7.79

$0.16 \quad 4.38$

$0.01 \quad 0.05$
0

4.01

$29.51 \quad 0.28$

$0.82 \quad 5.28$

24.0

78.96

$\mathrm{FeCrP}^{4}$

22.30

$\begin{array}{lllllll}2.81 & 3.99 & 21.99 & 46.24 & 0.00 & 0.11 & 2.56\end{array}$

100

Notes: ${ }^{1}$ Calculated from stoichiometry of oxide species; ${ }^{2}$ Average of 9 analyses of FeCrP contaminated by matrix; ${ }^{3}$ Average of 10 matrix analyses (low total due to analysis of all species as elements, whereas some are oxides, and neglect of water; all Fe assumed to be $\mathrm{FeO}$ ); ${ }^{4} \mathrm{FeCrP}$ analysis after subtraction of matrix, so total is constrained to be $100 \%$ 
Table 2. Compositions ( $\mathrm{wt} \%$ ) of the phyllosilicate matrix from Kaidun samples $3.10 \mathrm{j}$ and 53.10

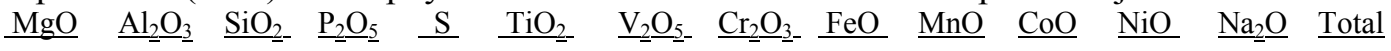

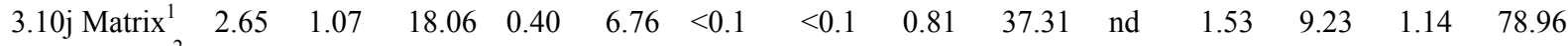

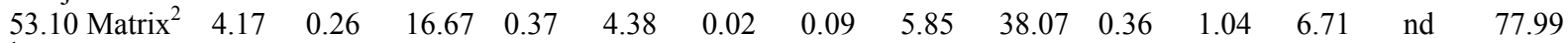

average of 6 analyses

${ }^{2}$ average of 8 analyses

nd : not determined 
Table 3. Fractional atomic coordinates for andreyivanovite

Cell Parameters: $a=5.8330 \quad b=3.5690 \quad c=6.6580 \quad \alpha=90 \quad \beta=90 \quad \gamma=90$

SPACE GROUP: Pnma

\begin{tabular}{|c|c|c|c|c|}
\hline Atom & Site & $\mathrm{x} / \mathrm{a}$ & $\mathrm{y} / \mathrm{b}$ & $\mathrm{z} / \mathrm{c}$ \\
\hline $\mathrm{Fe}$ & $4 \mathrm{c}$ & $0.144(8)$ & 0.25 & $0.561(3)$ \\
\hline $\mathrm{Cr}$ & $4 c$ & $0.027(2)$ & 0.25 & $0.171(5)$ \\
\hline $\mathrm{P}$ & $4 c$ & $0.766(7)$ & 0.25 & $0.623(7)$ \\
\hline
\end{tabular}


Table 4. Calculated XRD pattern for andreyivanovite, calculated using the XPOW program

\begin{tabular}{|c|c|c|c|c|c|}
\hline $2 \theta$ & $\underline{\mathrm{d}(\mathrm{calc})}$ & \multicolumn{4}{|c|}{$\underline{\mathrm{h}} \mathrm{k} \quad 1 \underline{\mathrm{I}(\mathrm{Calc})}$} \\
\hline 20.24 & 4.387 & 1 & 0 & 1 & \\
\hline 26.78 & 3.329 & 0 & 0 & 2 & \\
\hline .93 & 2.891 & 1 & 0 & 2 & \\
\hline .34 & 2.769 & 1 & 1 & 1 & 10 \\
\hline .92 & 2.258 & 2 & 1 & 0 & 46 \\
\hline .14 & 2.247 & 1 & 1 & 2 & 100 \\
\hline .15 & 2.194 & 2 & 0 & 2 & 13 \\
\hline 26 & 2.139 & 2 & 1 & 1 & 81 \\
\hline .64 & 2.074 & 1 & 0 & 3 & 31 \\
\hline .29 & 1.885 & 0 & 1 & 3 & 34 \\
\hline .72 & 1.869 & 2 & 1 & 2 & 10 \\
\hline .79 & 1.866 & 3 & 0 & 1 & 31 \\
\hline .92 & 1.793 & 1 & 1 & 3 & 20 \\
\hline 1.19 & 1.785 & 0 & 2 & 0 & 43 \\
\hline .76 & 1.766 & 2 & 0 & 3 & 10 \\
\hline 1.67 & 1.679 & 3 & 0 & 2 & 15 \\
\hline 5.18 & 1.665 & 0 & 0 & 4 & \\
\hline 5.57 & 1.654 & 3 & 1 & 1 & \\
\hline 7.59 & 1.601 & 1 & 0 & 4 & \\
\hline .29 & 1.583 & 2 & 1 & 3 & \\
\hline .62 & 1.463 & 3 & 0 & 3 & \\
\hline .53 & 1.425 & 4 & 0 & 1 & \\
\hline 7.68 & 1.384 & 2 & 2 & 2 & \\
\hline 9.48 & 1.353 & 1 & 2 & 3 & 12 \\
\hline 0.50 & 1.336 & 4 & 0 & 2 & \\
\hline 71.28 & 1.323 & 4 & 1 & 1 & \\
\hline 72.86 & 1.298 & 1 & 0 & 5 & 22 \\
\hline 73.41 & 1.290 & 3 & 2 & 1 & 15 \\
\hline 75.78 & 1.255 & 2 & 2 & 3 & \\
\hline 76.09 & 1.251 & 4 & 1 & 2 & \\
\hline 76.33 & 1.248 & 0 & 1 & 5 & \\
\hline 78.17 & 1.223 & 3 & 2 & 2 & 10 \\
\hline 78.60 & 1.217 & 0 & 2 & 4 & \\
\hline 79.05 & 1.211 & 2 & 0 & 5 & \\
\hline 80.60 & 1.192 & 3 & 1 & 4 & 16 \\
\hline 80.63 & 1.192 & 1 & 2 & 4 & \\
\hline 84.46 & 1.147 & 2 & 1 & 5 & \\
\hline 85.93 & 1.131 & 3 & 2 & 3 & \\
\hline 87.65 & 1.113 & 4 & 2 & 1 & \\
\hline 88.83 & 1.102 & 2 & 3 & 0 & \\
\hline 88.97 & 1.100 & 1 & 3 & 2 & \\
\hline 89.31 & 1.097 & 4 & 0 & 4 & \\
\hline 89.63 & 1.094 & 5 & 1 & 1 & \\
\hline
\end{tabular}

Notes: $\mathrm{CuK} \alpha$ radiation; reflections with $\mathrm{I}>1$. 


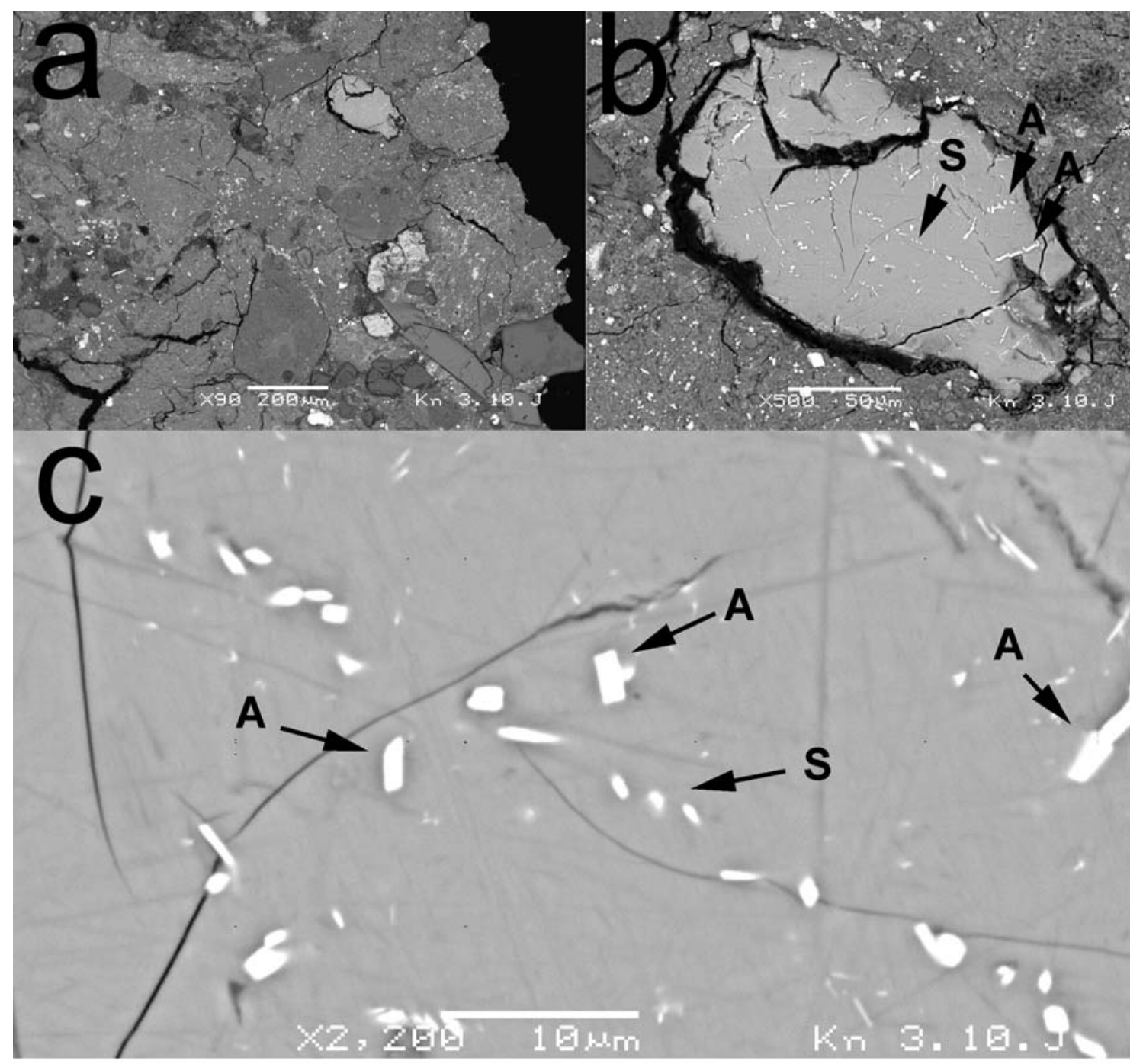

\section{Figure 1}

Figure 1. Backscattered electron images of the andreyivanovite-bearing clast in Kaidun section 3.10.j. (a) Low-magnification image of Kaidun, with the andreyivanovite-bearing clast at upper right (light grey). Scale bar measures $200 \mu \mathrm{m}$. (b) Medium-magnification image of the entire clast from (a). Scale bar measures $50 \mu \mathrm{m}$. (c) High-magnification image of serpentine (grey) containing crystals of andreyivanovite (FeCrP) crystals (A) and Fe-Ni-Cr sulfides (S). Scale bar measures $10 \mu \mathrm{m}$. 


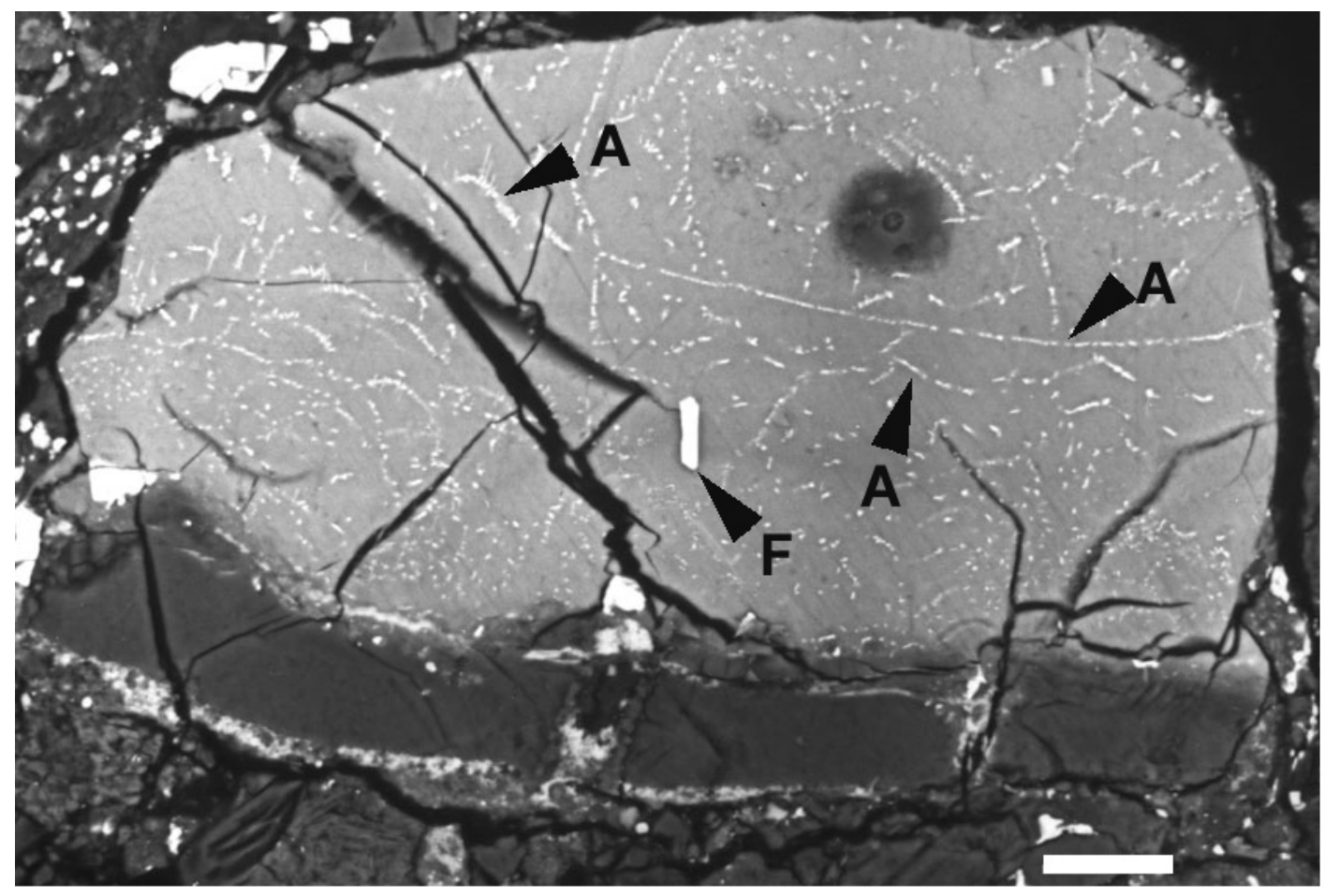

\section{Figure 2}

Figure 2. Backscattered electron image of serpentine (grey) containing lines of andreyivanovite crystals (A) in the original Kaidun occurrence (section 53.10), in association with florenskyite (F) and sulfide-bearing serpentine matrix (grey). Scale bar measures $20 \mu \mathrm{m}$. 


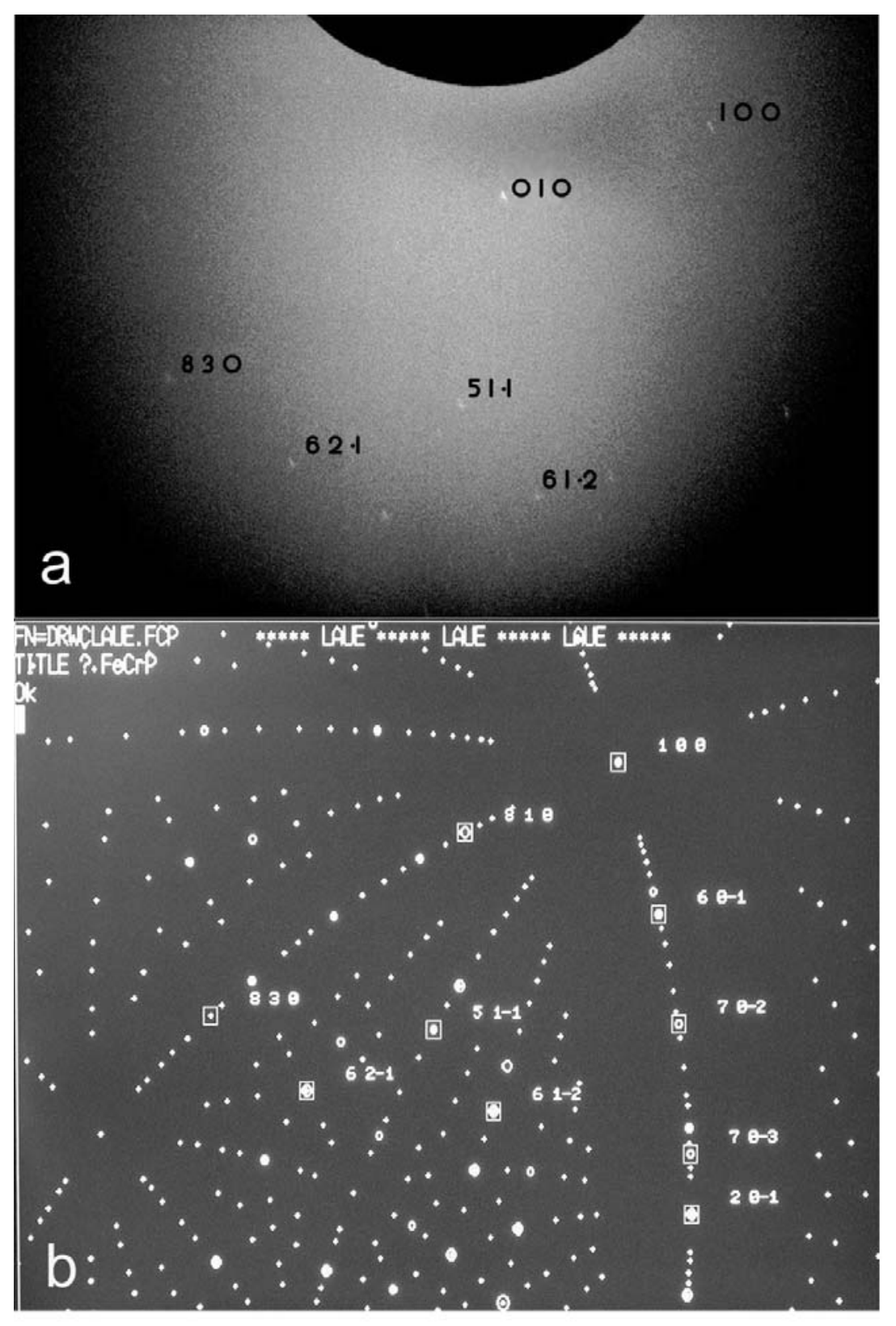

\section{Figure 3}

Figure 3. Laue pattern of a single grain of FeCrP, which consists of two distinct crystallites. (a) Observed Laue pattern of the FeCrP grain, with indexing shown for the most intense diffraction spots. (b) Calculated Laue pattern for this grain, showing two superposed diffraction patterns for the two crystallites - one shown as small closed symbols, and the other as larger open symbols. 


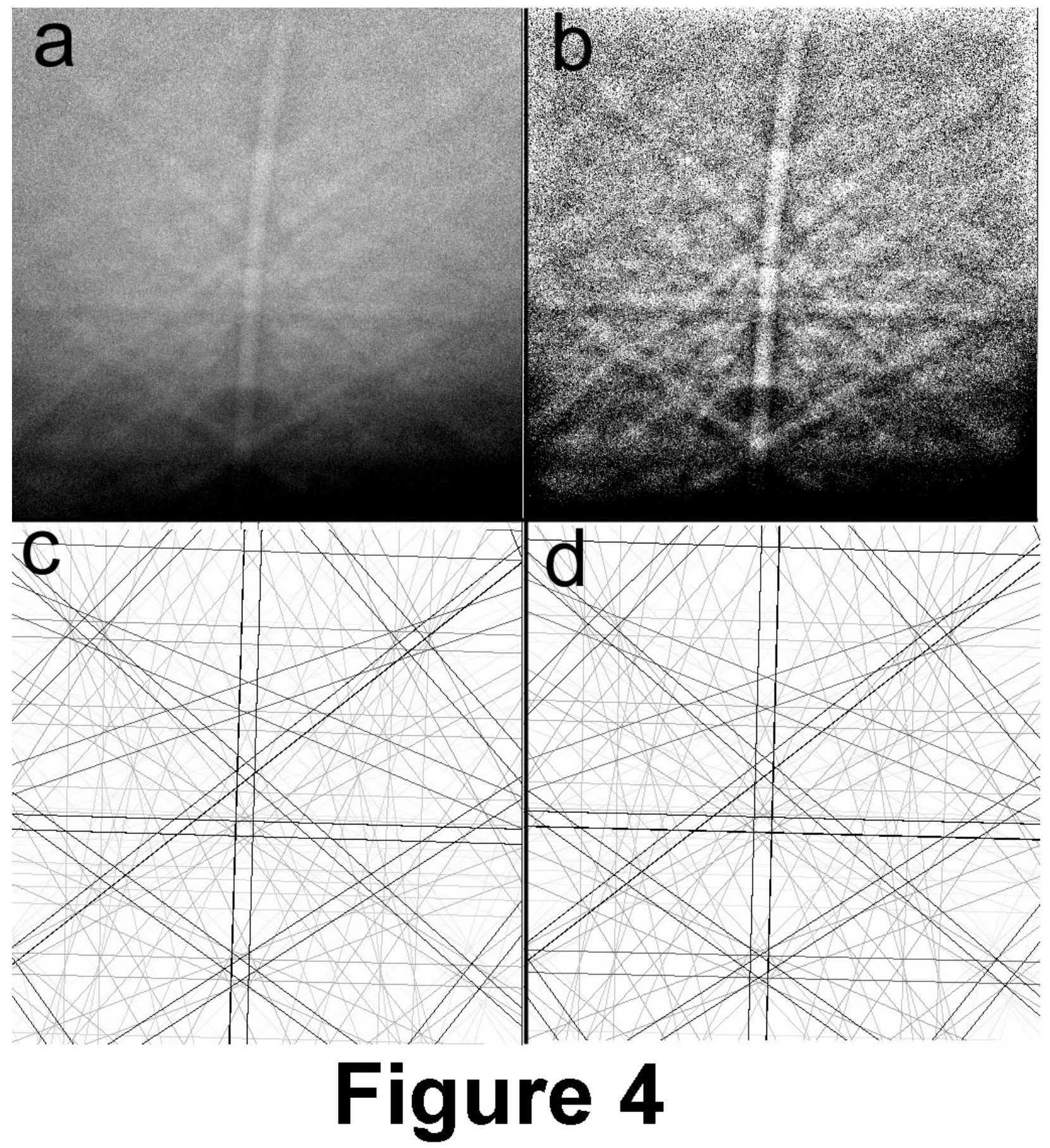

Figure 4. Observed (a-b) and calculated (c-d) EBSD patterns of andreyivanovite. The observed pattern on the right (b) has been contrast-enhanced from image (a) to show additional detail. (cd) illustrate the calculated EBSD pattern - the same pattern is shown twice to facilitate comparison of the calculated to observed patterns. 

Documentation that this mineral has been approved by the IMA New Mineral Commission:

Please go to http://www.geo.vu.nl/users/ima-cnmmn/minerals06-04.pdf

Which is the April 2006 report of the CNMMN

And see mineral proposal 2006-003, which is for andreyivanovite 